\title{
Internet Finance Faces Risks and Countermeasures
}

\author{
Xinyi $\mathrm{Wu}^{1, *}$ \\ Shanghai GuangHua Qidi College, Shanghai, China, 200000 \\ *Corresponding author. Email: wu00400301@163.com

\begin{abstract}
Internet finance is a new financial business model. It is a model where the conventional business organizations perform financing, payment, investment by using the internet and information technology. The internet finance models include payments, online lending, equity crowdfunding, fund sales, insurance, trust, and consumer financing all in performed through internet. It is considered as the third way in performing financial activities. This paper is going to elaborate the overview on internet finance, the impact of internet finance to the stakeholders, risks faced using this model and the countermeasures to overcome the risks. It does not focus to any country or region. It is a general article explaining the internet finance.
\end{abstract}

Keywords: Internet finance, mobile payments, internet transactions, commercial banks, traditional finance

\section{INTRODUCTION}

The internet financing has started to evolve in the 21 st century where it started at the back-end system in financial institutions. The technology then swap to consumer-oriented services. The internet financing is not now only used by the financial institutions, also other sectors such as education, fundraisers, retail banking and investment managements. Internet financing also involve in the emerging of crypto-currencies such as bitcoins. The internet is started to grow, as well as the tools i.e. smartphones has supported the internet financing to grow. Previously, the internet technology only referring to the computer technology which only supports the back office of banks and businesses, not with the revolution, it has moved towards the technological intervention into individual consumers and commercial finance. The internet financing involves from digital money up until the bookkeeping. [1]

The basic function of the financial institution is to transfer money between those in need and those who is having extra money. There are two main reasons why the financial intermediaries appear which are they are able to provide the technologies to reduce the transaction costs and the second one is financial intermediaries through internet finance is a master to the information processing which may reduce the risks of moral hazard because of the information asymmetry.
The financial intermediaries are commercial banks (indirect financing) and the security markets (direct financing). The existence of internet finance is huge paradigm to the financial sectors. [2]

\section{INTERNET FINANCE}

As mentioned the involvement in internet technologies has pushed the development of the financial industries. The internet finance or what we called as peer-to-peer (P2P) lending which act as the middle person that connect from the need money and money source. Due to the financial crisis and the downturn of the commercial banks, the lending service through internet finance is a heroic move. Examples of the internet finance are LendingClub and Prosper are two platforms that hold the major market share in internet finance in the US. The platform has gather the lenders and the borrowers. The P2P loans sites has able to reached up to USD2.4 billion loan volumes in 2013. Historically, back in 2006, LendingClub able to issue USD4 billion loans and then USD2.3 billion by 2013. As for in China, the internet finance platform started launched in 2007. It is then started to gain its popularity and market recognition. The first internet lending platform in China is PPdai which inspired as internet finance in US. [6] 

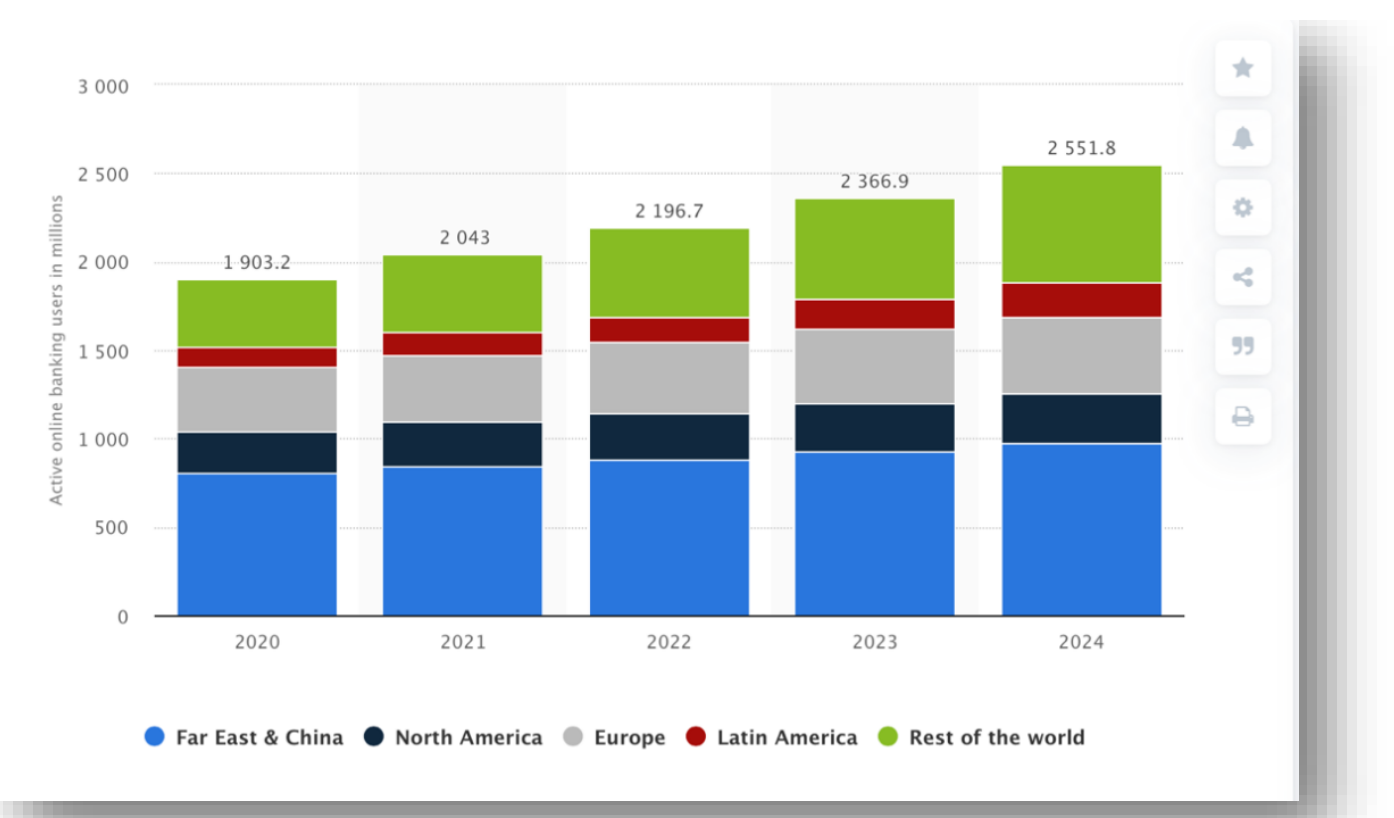

Figure 1. Number of active online banking users in 2020 and the 2021 to 2024 forecasts worldwide, based on the region.

Source: Statista Research Department, Apr 14, 2021 [8]

Illustration 1.0 shows the growing of the internet finance worldwide in 2020 and the forecast for the year 2021 to 2024. From the illustration, it shows that the trend of the internet finance worldwide in total of $1,903.2$ million users in 2020. The trend is forecasted to be increased steadily from 2021 to 2024 . The highest market share of the internet finance in the 5 years is the Asian region while the least is by the Latin America region. In 2024 , it is forecasted that the volume of users will increase by $34 \%$ into $2,551.8$ million users. This is a proof where the internet finance has increase the finance transactions globally. [8]

\subsection{The Impact of Internet Finance to the Commercial Banks}

Commercial banks as everyone knows, that is the financial institution that receive deposits, provide loans and offers investment products to the consumers. The main profit souces are from business asset, liability business to the consumers and the intermediary business. Usually, the commercial banks only deals with the priority customers - high value customers. Thus, the small and medium sized customers has been neglected. This is where the internet finance comes into place where its provides the opportunity for the neglected group of people. The interest rate of the internet finance offered to the customers are generally high. Thus, it does not concern much on the asset business like the normal commercial banks do.

The internet finance has affect the deposit into the commercial banks. For instance, online wealth management products has approached the customers differently, and offered a higher yield. As a result, the consumers has started to shift towards the internet financial management to enjoy it. This has pushed the commercial bank to develop its own online wealth management platforms and this has pushed towards a slight improvement in deposits area.

The development of the third-party payment gateway, it has slightly threaten the intermediary business of the commercial banks. The relationship between the bank and the customers become better because the customers may use the third-party payment gateway for online payments, investments and wealth management. This has hinder the development of the intermediary business by the commercial banks.

From the arguments above, it shows that internet finance do have adverse effect to the commercial banks and at the same time it stimulate the commercial banks to evolve in terms of their approach with the customers, their service quality and structure, reduce the operating costs and later these will help them to improve their profitability. [3]

\subsection{The Impact of Internet Finance to the Traditional Finance}

\subsubsection{Increase the financial transactions}

The wide usage of internet technology, many people have starts to become more technology savvy and use the technology as the medium to perform monetary transactions via mobile phone, laptops, tablets and others. Performing payment via online can solve many problems that might be faced through the physical bank. People can save a lot of time when they may perform the transactions without having to leave their home. This 
influence the people's habit. This has cause the financial transactions trends changed. Nowadays, through the internet finance technology, most of the transactions are conquered by the living expenses transactions such as utilities and communications expenses.

\subsection{Change the capitalization model of the businesses}

Through the conventional financial industry, the corporate funds need to implement the model of traditional capital supply and it is depends on the profitability of the supply funds. But through internet finance, the financing model have changed and adopt a different way. Small businesses especially do not have to bear with the restrictions imposed by the traditional financial institutions to apply for funding. They may use the internet to manage their business wealth. It is more convenience. Due to this, the traditional financial institution has improvise their evaluation system to adapt with the change in the supply and demand of the funds. Many investment companies has started to joint venture with the e-commerce websites to launch their financial products without need to have physical contact. [5]

\section{POTENTIAL RISK OF INTERNET FINANCE MARKET}

Internet finance need a proper monitoring and regulation compliance as it is a channel to link the lenders and the borrowers. This cause the disadvantage to the internet finance platforms as to implement proper regulations and monitoring need a high cost. This will lead to the bankruptcy when the repayment of the loans cannot be made, fraud and other financial risk. The development in the internet finance will cause negative impact to the commercial banking industries as mentioned in the above paragraphs. [7]

\subsection{Governance and Ethic Risk}

Indeed, the internet finance market started to emerge as the time goes by. However, the platforms established were not maintained properly. In the event when there is default borrowers, the platform owners will receive the consequence. The platform owner will be held responsible to repay the money to the lenders. According to National Business Daily dated 21st January 2014, in Hangzhou, Shanghai and Shenzhen, approximately 231 million yuan of loans value involved through the internet finance platforms scandals. This happened then the platform owner disregard their obligation on the lenders and the borrower. This has cause fear towards the internet finance and loan among the society. Some of the member of the society even has launched riot to express their anger towards the irresponsible platforms about their lost in their investment. In other point of view, the riot established by the investors has pulled the government's attention into this case and prepare a rescue plan.

\subsection{Reputational Risk}

The platform also faced the reputational risk caused by their stakeholders i.e. the investors and the borrowers. This happen when the borrowers unable to pay the loans and the investors have to close their business because of losses and not able to provide profits to the platforms. The possibility of the platform owner run away and shut the platforms down. As a result, the investors will not receive their dividend as agreed earlier. This this will affect the platform's reputation moving forward.

\subsection{Operational Risk}

The risk in operational side also may happen. Internet finance which mainly depends on the technology, operations and laws may be easy to be affected to the three factors. The technology risks incurred by the loan issuance occur when the loan issued based on the data analysis available in the system. The data maybe obsolete, false compare to the manual investigation that usually done by the commercial institutions. Thus, the decision of issuing the loan to a borrower maybe wrong due to the false data provided. The market change also caused the mismatch of information as usually, the changes will not automatically updated into the system. It might takes time until the system update happens. The local government legislation may affect the readiness of the platform to operate. For instance, the China governments law on the internet finance might not be as extensive as the us Government. The China laws and regulation on finance are based on the traditional finance activities. This there is no clear right and rules to protect the interest of the parties involved in the internet finance. In China, the government did not set the characteristics of the identification of internet finance platforms, and the contract validity.

\subsection{Labor Market Risk}

The involvement in technology in managing the finance caused the reduction of necessity to have the human workers in the financial industry. The labor division will be replaced by the internet and other related technologies. Corporate institution and individual consumers will perform all monetary transactions through the internet. The complicated job such as risk sharing and maturity matching will be disentangled, all will be easier and some of the process will be cut off and does not need human interreference. People will lose their jobs and due to the fast moving of technology, some of the current skills of the labor worker may be obsolete. [6] 


\section{COUNTERMEASURE TO OVERCOME THE POTENTIAL RISK OF INTERNET FINANCE MARKET}

\subsection{Law and legal requirements improvement}

For the government's law which are not comprehensive enough to cover the overall aspects of the internet finance, it is difficult to govern the internet finance activities. The regulators should enhance the local law so that it covers the overall internet finance activities and the parties involved in it. The government must be proactive in amending the laws and regulations as internet finance will evolve together with technology. They also may identify the current established regulations for any loopholes and may use the other country's regulation as the reference to perform improvements.

\subsection{Establish the multi-level internet finance risk monitoring system}

The regulators should establish the internet finance risk monitoring system. The government may establish a database that can trigger the government of any potential risk. Internet finance may cause the financial crisis. The database will act as the first line of defence that will identify the potential risk through the large volume of data monitoring system.

Next is, the government may established a consolidated regulatory assessment system. Like in financial institutions in China mainly they are using different rating system. For example, the CBRC establish CAMELS rating system for the banking industry. The increase in financial institutions unfortunately not have any regulatory agencies that may oversight their rating assessment, business and credit situation. A regulatory body should be established to monitor the activity of the internet finance platforms to avoid any loopholes to commit crime.

\subsection{Enhancement of Internet Financial Users}

Protection of Internet Finance users is very important as they maybe the victims of the unregulated platforms. The users include the investors, lenders, borrowers and also the platform owners. The way to protect the interest of the users are by educating them and ensure they have a deep understanding on the risk of internet finance system and its products. They should understand the safe use of the system, the risks, the characteristics of the legit platforms and others.

\subsection{Foster the International Cooperation and Knowledge Exchange, and International Financial Monitoring.}

The parties responsible for the monitoring activities is the government's and its authorized organizations. The exchange of knowledge is needed to learn how the enforcement of the Internet Financial Law, establishment of the regulatory bodies especially with the more experience governments. [9]

\section{CONCLUSION}

This paper presented the briefly on the internet financing background, the impact towards the commercial banks and the traditional finance, the risk raised by the internet finance and the ways to overcome the risks. Internet finance has been increasing and started to popular since 2006 from US and its followed by China in 2007. The users is projected to increase further until 2024. Despite of that, there are many impact towards the commercial banks and the traditional finance. Of course, they are the negative impact and this is one of the risk arise by the internet finance. Other risks are the governance and ethic risks, operational risks, reputational risks and labor market risks. Countermeasures also been suggested in this paper to the government as they hold the power to govern the country. Due to the unexpected increase in the internet finance platforms, the government's current laws to govern the finance markets does not cover the internet finance, thus the government need to take action. Apart from that, the government need to take action because internet finance may cause financial crisis and labor market downturn.

\section{AUTHORS' CONTRIBUTIONS}

This paper is independently accomplished by the author.

\section{ACKNOWLEDGEMENTS}

I would like to express my appreciation to my lecturer who have taught me this course. It has enlighten me with knowledge especially the current financial issues globally. Thank you to my parents who always support me until I able to reach to this extend. Not to forget my classmates, who supported me during the classroom and accomplishing the course tasks.

\section{REFERENCES}

[1] Kagan.J, 2020, Financial Technology - Fintech, Investopedia, Retrieved from: https://www.investopedia.com/terms/f/fintech.asp\# fintech-users 
[3] Dong. J, Yin. L, Liu. X, Hu. M, Li X and Liu.L, 2019, Impact of Internet Finance on the Performance of Commercial Banks in China, International Review of Financial Analysis, 72 (2020), Doi: https://doi.org/10.1016/j.irfa.2020

[4] Liu.J, 2018, Research on Internet Finance: its Business Models and Development Trend, International Conference on Business and Information Management, pp. 169-172, doi: https://doi.org/10.1145/3278252.3278253

[5] Xiaorui. X, 2018, The Impact of Internet Finance on Traditional Finance, Topics in Education, Culture and Social Development, 1(1): 66-67

[6] Tian. Z, \& Hassan. A, 2019, Internet Finance and its Potential Risks: the Case of China, International Journal of Accounting, Finance and Business (IJAFB), Vol. 4 (20), pp. 45-51.

[7] Chen, Z. Li, Y. Wu, Y. and Luo, J. (2017). The transition from traditional banking to mobile internet finance: an organizational innovation perspective - a comparative study of Citibank and ICBC. Financial Innovation 3:12 DOI 10.1186/s40854-017-0062-0.

[8] Statista Research Department, 2021, Online Banking Users Worldwide in 2020 with Forecasts to 2024, by Region Retrieved from: https://www.statista.com/statistics/1228757/onlinebanking-users-worldwide/

[9] Xu. H, 2017, China's Internet Financial Risks and Countermeasures, 2017 International Conference on Financial Management, Education and Social Science (FMESS 2017), UK. 